\section{Pitfalls in isolating lipid rafts}

The recent Review by Allen et al. on lipid raft microdomains and neurotransmitter receptor signalling ${ }^{1}$ provides an excellent overview of important structural and functional aspects of these specific membrane microdomains, with a particular focus on their role in the nervous system. Nevertheless, we would like to emphasize two important aspects. As outlined in the Review, the valid and reproducible isolation of lipid rafts is not trivial, but mandatory to draw correct conclusions. Inconsistencies in raft isolation procedures, for example the type, amount and duration of detergent use, make results difficult to compare and may contribute to some controversies in the field. A particularly important issue is the presentation of both a positive and a negative control. Mostly, caveolin 1 or flotillin 1 are used as raft marker proteins ${ }^{2-4}$, whereas the transferrin receptor or other proteins such as the $\mathrm{Na}^{+} / \mathrm{K}^{+}$-ATPase are reported as non-raft proteins ${ }^{5-7}$. Only a few studies show convincing data of a clear separation of raft from non-raft proteins ${ }^{5,6,8}$. This separation relies highly on the preparation procedure, in particular the use of detergent, for which the type of

A

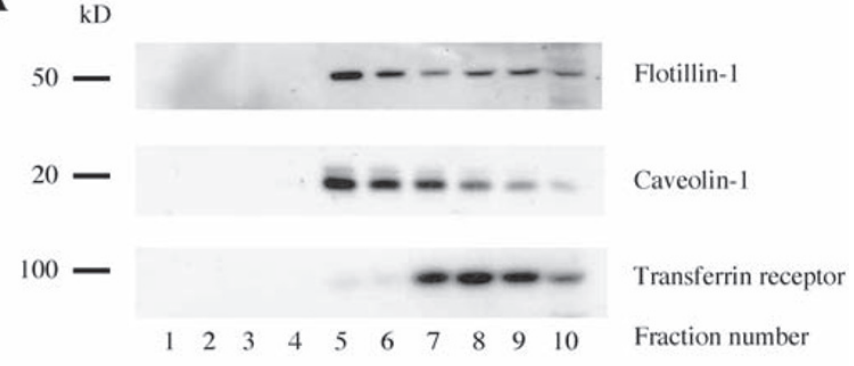

B

$\mathrm{kD}$

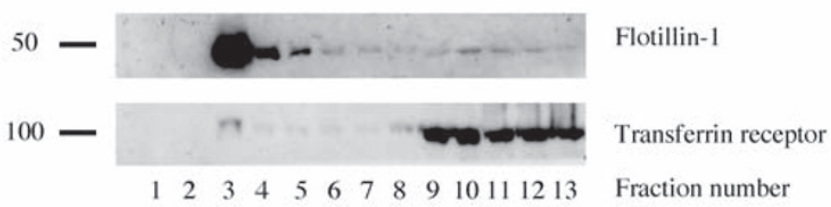

Figure 1 | Separation of caveolin 1 and flotillin 1 from the transferrin receptor in fractions obtained from density gradient centrifugation. HEK 293 cells (A) and native cortical mouse brain tissue (B) were homogenized in a high-salt buffer and were subsequently brought to a discontinuous iodixanol (A) and sucrose (B) gradient. After ultracentrifugation ( 4 hours, $4^{\circ} \mathrm{C}, 40,000 \mathrm{rpm}$ in a Beckman SW 60 rotor) fractions were collected and analysed for caveolin 1 and flotillin 1 and the transferrin receptor by Western blotting. For the preparation of rafts from HEK 293 cells, $1 \%$ Triton X-100 was directly added to the saline buffer, whereas for the preparation of rafts from brain tissue, the homogenate was separately incubated with $2 \%$ Triton X-100 for 30 minutes on ice. detergent, the concentration and the duration of incubation are the main determinants. Furthermore, the preparation procedure should be chosen according to the type of tissue under investigation. An example from our laboratory, in which we isolated caveolin 1 and flotillin 1 as raft-associated proteins and the transferrin receptor as a non-raft protein, illustrates this need to vary conditions for different tissue types (FIG. 1). When investigating the concentration of detergent and incubation time needed to separate raft from non-raft proteins within the range reported in the literature $e^{5,6}$, we also observed a dose-response relationship ${ }^{8}$. Future studies should therefore clearly demonstrate that the method selected is appropriate for the tissue type under investigation to separate raft from non-raft proteins when claiming raft association of particular proteins.

Our second comment is on our previous work, which, as the authors correctly cited, showed that psychopharmacological drugs such as antidepressants and antipsychotics can accumulate in raft-like domains ${ }^{9}$. We would like to point out that not all psychopharmacological drugs accumulate in these microdomains. This differential enrichment of antidepressants and antipsychotics in lipid rafts may contribute to their effects on neurotransmitter receptor signalling - for example, the allosteric modulation of ligand-gated ion channels - and thus to the effects of psychopharmacological compounds on neuroplasticity.

\section{Caroline Nothdurfter ${ }^{*}$, Gerhard Rammes ${ }^{\ddagger}$, Theo Rein ${ }^{\ddagger}$ and Rainer Rupprecht*}

\section{Author affiliations}

* Department of Psychiatry, Ludwig-Maximilian-University, 80336 Munich, Germany. ${ }^{\ddagger}$ Max-Planck-Institute of Psychiatry, 80804 Munich, Germany. ${ }^{\S}$ Department of Anesthesiology, Technical University of Munich, 81675 Munich, Germany.

Correspondence to R.R.

e-mail: Rainer.Rupprecht@med.uni-muenchen.de

\section{References}

Allen, J. A., Halverson-Tamboli, R. A. ¿ Rasenick, M. M. Lipid raft microdomains and neurotransmitter signalling. Nature Rev. Neurosci. 8, 128-140 (2007).

Jacobson, K. \& Dietrich, C. Looking at lipid rafts? Trends Cell Biol. 9, 87-91 (1999). Pike, L. J. Lipid rafts: bringing order to the chaos. J. Lipid Res. 44, 655-667 (2003). Morrow, I. C. \& Parton, R. G. Flotillins and the PHB domain protein family: rafts, worms and anaesthetics. Traffic 6, 725-740 (2005).

5. Chamberlain, L. H., Burgoyne, R. D. \& Gould, G. W. SNARE proteins are highly enriched in lipid rafts in PC12 cells: implications for the spatial control of exocytosis. Proc. Natl Acad. Sci. 98, 5619-5624 (2001).

6. Hering, H., Lin, C. C. \& Sheng, M. Lipid rafts in the maintenance of synapses, dendritic spines, and surface AMPA receptor stability. J. Neurosci. 23, 3262-3271 (2003).

7. Eckert, G. P., Igbavboa, U., Muller, W. E. \& Wood, W. G. Lipid rafts of purified mouse brain synaptosomes prepared with or without detergent reveal different lipid and protein domains. Brain Res. 962, 144-150 (2003).

8. Brady, J. D et al. Functional role of lipid raft microdomains in cyclic nucleotide-gated channel activation. Mol. Pharmacol. 63, 504-511 (2004).

9. Eisensamer, B. et al. Antidepressants and antipsychotic drugs colocalize with $5-\mathrm{HT}_{3}$ receptors in raft-like domains. J. Neurosci. 25, 10198-10206 (2005). 